\title{
The Effects of Age, Study Time, and Importance of Text Units on Strategy Use and Memory for Texts
}

\author{
Beth E. Kurtz \\ Wolfgang Schneider
}

\author{
Max Planck Institute for Psychological Research, \\ Munich, F.R.G.
}

This study investigated study behavior and recall of a narrative text as a function of the reader's age, study time, and importance level of text units. Fifth graders, seventh graders, young- and older adults were asked to read a fairy tale, and do anything they liked to prepare for verbatim recall. Half of the subjects in each age group were assigned to an immediate recall condition; half were given additional study time. Examination of recall data showed that all subjects showed higher recall of important units in the text than unimportant units. This effect was independent of age and study time condition. Study behaviors varied significantly across age groups and study conditions: while adults underlined or took notes with equal frequency, children preferred note-taking as a study strategy. With additional study time, fifth graders, seventh graders, and older adults increased their strategic behavior; young adults did not.

Remembering what one has read is something to which we all aspire. Such rememberance is facilitated by the ability to abstract the gist - or the most important points - from a text. This ability has been shown to improve between fifth and twelfth grades, or - in other words - homogeneity of importance judgments increases during this period (Brown \& Smiley, 1977, 1978; Brown, Smiley \& Lawton, 1978; Denhière, 1980; Denhière \& Le Ny, 1980). In two developmental studies, Brown and colleagues reported that third graders made no reliable distinctions according to importance level; fifth graders were able to isolate only the most important units of prose; and seventh graders produced ratings similar to those of young adults, except their classifications of units of medium importance were not as fine-tuned as those of adults. Denhière and Le Ny (1980) showed that adults' importance judgments are in close agreement with the judgments of 11-year-olds, but not with those of 8-year-olds.

Recall of prose passages by both children and adults follows the adult-rated importance hierarchies. That is, regardless of study time and study behavior, a greater number of important units are recalled than unimportant units (Brown \& Smiley, 1978; Brown, Smiley, Day, 
Townsend \& Lawton, 1977; Denhière \& Legros, 1987; Moore \& O'Driscoll, 1983), and this recalls follows the importance rankings of adults and 11-year-olds rather than the rankings of 8-year-olds (Denhière \& Le Ny, 1980). Furthermore, Brown and Smiley found that with additional study time, adult recall improved as a function of importance level: college students recalled more units of the two most-important categories, but the same number of unimportant units as students with less study time. Seventh graders showed the same recall pattern, although less pronounced, while fifth graders' recall did not improve at any level with additional study time (Brown \& Smiley, 1978).

From a theoretical viewpoint, it is not clear why mature readers should improve only their recall of important units with additional study time. To the contrary, since Brown and Smiley's (1978) young adults recalled approximately three times as many important units as unimportant units in the immediate recall condition (approximately $60 \%$ to 20\%), it might be expected that with additional study time, their recall of unimportant units would show the greatest improvement. In an investigation of Papua New Guinean university students Moore and O'Driscoll (1983) failed to replicate Brown and Smiley's findings. Just as with Brown and Smiley's fifth graders additional study time did not result in improved recall at any importance level.

Brown and Smiley posited that mature readers' recall patterns are due to their advanced metacognitive awareness: they have a better understanding of the relative importance of text units than younger readers do and of the usefulness of studying selectively. They focus on important units in texts, use study strategies like note-taking and underlining selectively, and in the end remember more important units than do younger readers; this difference increases with additional study time. The study behaviors of Brown and Smiley's subjects supported this argument. That is, with additional study time, older readers underlined a greater number of important text units than younger readers did (Brown \& Smiley, 1978).

We are arguing, however, that metacognitive processes are not necessarily implicated either by subjects' recall patterns or by their study behaviors. Study behaviors are cognitive tactics used to reach learning or problem-solving goals. They may be beneficial in reaching a goal without being metacognitively informed. Other factors might be responsible for the tendency of older readers to recall more important (versus unimportant) information: the saliency of the material, readers' previously acquired schemas for story patterns, previous knowledge. Similarly, the underlining of certain phrases might reflect the readers' perceptions of the role that information plays in the text, rather than resulting from metacognitive knowledge about reading and reading-to-remember strategies.

Although we call attention to this theoretical question, it was beyond the scope of the present study. Before attempting to measure the possible metacognitive processes involved, we aimed to test the robustness of Brown and Smiley's findings. Thus, one purpose of this study was to replicate Brown and Smiley's (1978) study with a European sample. In particular, we examined the effect of additional study time on recall of prose units as a function of importance level. In addition to testing fifth graders, seventh graders, and young adults, we included a middle - to older - adult group to examine prose recall across the life span. A second purpose of the experiment was to investigate the use of study strategies in the four age groups. If mature readers deliberately focus on a subset of text units, this behavior should be evident in their use of study strategies. Thus, we were interested both in the variation of study behavior across age groups and study time conditions and in the relationship between study behaviors and recall.

We hypothesized that our younger and older adults would show mature recall patterns; that is, they would recall the greatest percentage of important units, an intermediate number of medium units, and a small percentage of unimportant units in comparison to the recall protocols of fifth graders. Further, we anticipated that seventh graders' protocols would resemble the adult pattern, but be less pronounced. Secondly, we hypothesized that school-aged subjects would be more likely to engage in study behavior than would older adults, and that deliberate study behavior at all ages would result in improved recall. 


\section{Method}

\section{Subjects}

67 fifth graders, 63 seventh graders, 67 young adults, and 53 older adults participated in the investigation. All fifth and seventh graders were pupils at public junior high schools (Gymnasien) in Munich, West Germany (CA $=11.5$ and 13.8 , respectively). The adult subjects attended local continuing education classes. Young adults ranged in age from 19 to 35 ; the older adults ranged from 36 to 70 .

\section{Materials and procedure}

All testing was conducted in groups of 5 to 18 participants. Subjects were randomly assigned to groups for immediate or additional study time conditions. Two texts of fourth grade reading level were used as stimulus materials, «Mr. Moritz becomes Bald», and «Dr. Know-it-All». Both texts had been divided into idea units, and the idea units had been classified by adult raters into four importance levels after the method described by Johnson (1970). «Mr. Moritz» contained 588 words and 104 idea units, and «Dr. Know-it-All» contained 497 words and 96 idea units. Pilot testing indicated that the two texts were approximately equal in difficulty.

Each subject received a copy of the text, a felt tip pen and scratch paper, and was told that verbatim recall (i. e. writing word for word as much of the story as possible) would be requested later. The experimenter also told the subjects that they should feel free to write on the paper that was provided, on the text itself, or do anything they liked in order to help themselves remember the story. Next, the experimenter read the story aloud while subjects followed along at their desks. The story was read slowly so that subjects had some opportunity to take notes or underline if so they wished. Subjects in the immediate recall condition heard the text read once, then all papers were collected, lined paper was distributed, and subjects attempted verbatim recall of the text. Recall was performed without time restraints, and usually required 25 to 30 minutes.

In the additional study time condition, adults received an additional 5 minutes, and children received an additional 8 minutes to review the text before the papers were collected and recall was requested. Pilot work had shown that, for each group, the additional study time was approximately double the normal time required to read through the text once.

Recall protocols were scored to determine how many idea units at each importance level had been recalled. Scoring reliability among independent raters was $96 \%$. Study papers were scored according to whether or not the subjects employed note-taking or underlining as strategies. We attempted to record study behavior as a function of importance level. However, we could find no reliable way to code the data, since underlining and note-taking frequently covered partial units. Therefore, subjects were simply given a « 1 » or a « 0 » in each category, where «1» indicated underlining or note-taking of more than five words.

\section{Results}

The numbers of text units recalled within each importance level were divided by the total possible units (26 at each importance level for «Mr. Moritz», and 24 per level for «Dr. Know-it-All») for each subject to yield percent recall scores. These scores are displayed in Figure 1 as a function of age and study time conditions. Percent recall scores, labeled A to D from most important to least important, were summed up to create total recall scores for each subject. As can be seen in Figure 1, all age groups recalled more A units (most important) than B or C units (of medium importance), and more units of medium importance than of least importance. Furthermore, both adult groups clearly differentiated between the two levels of medium importance, while fifth and seventh graders recalled approximately the same numbers of $\mathrm{B}$ and $\mathrm{C}$ units. 
Figure 1. Proportions moyennes d'unités de rappel en fonction de l'âge des sujets et des temps d'étude
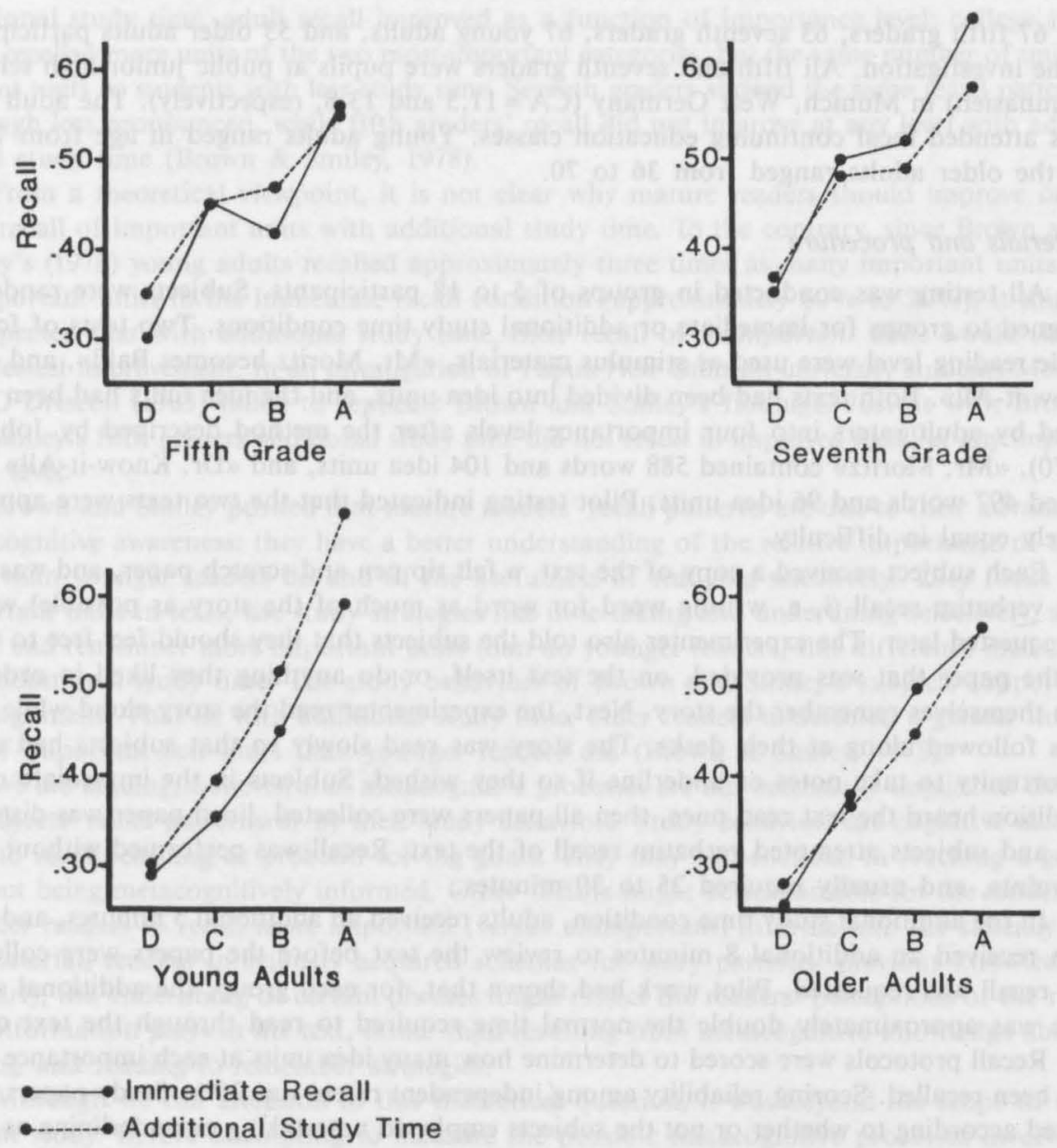

Figure 1. Mean proportions of units recalled within age groups and study time conditions

Preliminary analysis indicated no significant effects due to story or sex of subject; therefore, these factors were not included in subsequent analyses. Percent recall and total recall scores were analyzed in 4 (Age) $\times 2$ (Study Time) $\times 2$ (Study Behavior) analyses of variance, where the two levels of Study Time were immediate recall versus additional study time, and the two levels of Study Behavior were no note-taking or underlining versus some note-taking and/or underlining.

The analysis of variance on A units (most important) yielded a significant Age $\times$ Study Time $\times$ Study Behavior interaction, $F(3,234)=3.07, p<.05$. The Tukey test was used for posthoc comparisons among means. Harmonic means were used to adjust unequal cell sizes. Analysis of the three-way interaction showed that among subjects who neither underlined nor took notes, additional study time resulted in superior recall for young adults in comparison to fifth and seventh graders, $q_{\mathrm{T}}(12,243)=4.85, M S_{\mathrm{e}}=0.026$. Recall did not differ as 
a function of age for subjects who didn't use study strategies in the immediate recall condition. Differences among means for subjects who either took notes or underlined were nonsignificant across Age and Study Time conditions.

The Age $\times$ Study Time interaction on Recall A scores was also significant, $F(3,234)=3.72$, $p<.05$. Post hoc comparisons among means showed that recall only differed as a function of study time for the young adults who remembered more with additional study time $q_{\mathrm{T}}(8,243)=4.29$. The main effect of Age was also significant, $F(3,234)=3.93 p<.01$. Seventh graders and young adults recalled more $\mathrm{A}$ units than did fifth graders and older adults, $q_{\mathrm{T}}(4,243)=3.63, p<.01$. All other main effects and interactions were nonsignificant for Recall A scores.

The 4 (Age) $\times 2$ (Study Time) $\times 2$ (Study Behavior) analysis of variance on Recall B scores was insignificant for all main effects and interactions.

The analysis of variance on Recall $\mathrm{C}$ scores showed significant main effects of Age and Study Behavior, $F(3,234)=6.50, p<.05$, and $F(1,234)=4.94, p<.01$, respectively. Post-hoc comparisons among means showed that fifth and seventh graders recalled more $\mathrm{C}$ units than did young and older adults, and that subjects who took notes or underlined recalled more than subjects who used no study strategies, $q_{\mathrm{T}}(4,243)=3.63, M S_{\mathrm{e}}=0.034$. The main effect of Study Time and all interactions were insignificant.

The analysis of variance on Recall D scores showed a significant main effect of Age, $F(3,234)=3.54, p<.05$. Fifth and seventh graders recalled more D units than did the young and older adults, $q_{\mathrm{T}}(4,243)=3.63, M S_{\mathrm{e}}=0.026$. All other effects were nonsignificant.

The Age $\times$ Study Time $\times$ Study Behavior analysis of variance on total recall scores, summed across the four importance level categories, showed a significant main effect of Age, $F(3,234)=3.05, p<.05$. Seventh graders recalled more units than all other age groups, $q_{\mathrm{T}}(4,243)=3.63, M S_{\mathrm{e}}=0.317$. All other main effects and interactions were nonsignificant for total recall scores.

Table 1

Study behavior as a function of age and study time

\begin{tabular}{|c|c|c|c|c|}
\hline & $\begin{array}{l}\text { No Study } \\
\text { Behavior }\end{array}$ & $\begin{array}{l}\text { Underlined } \\
\text { Only }\end{array}$ & $\begin{array}{c}\text { Took } \\
\text { Notes Only }\end{array}$ & $\begin{array}{c}\text { Underlined } \\
\text { and } \\
\text { Took Notes }\end{array}$ \\
\hline \multicolumn{5}{|l|}{ Immediate Recall } \\
\hline $\begin{array}{r}\text { Grade } 5 \\
n=29\end{array}$ & 17 & 2 & 10 & . \\
\hline $\begin{array}{r}\text { Grade } 7 \\
n=36\end{array}$ & 15 & 1 & 20 & 0 \\
\hline $\begin{array}{l}\text { Young Adults } \\
\mathrm{n}=35\end{array}$ & 8 & 10 & 13 & 4 \\
\hline $\begin{array}{l}\text { Older Adults } \\
\mathrm{n}=25\end{array}$ & 6 & 9 & 7 & 3 \\
\hline \multicolumn{5}{|c|}{ Additional Study Time } \\
\hline $\begin{array}{r}\text { Grade } 5 \\
N=38\end{array}$ & 8 & 3 & 20 & 7 \\
\hline $\begin{array}{r}\text { Grade } 7 \\
\mathbf{N}=27\end{array}$ & 4 & 0 & 22 & 1 \\
\hline $\begin{array}{l}\text { Young Adults } \\
\mathrm{N}=32\end{array}$ & 15 & 4 & 12 & 1 \\
\hline $\begin{array}{l}\text { Older Adults } \\
\mathrm{N}=28\end{array}$ & 3 & 10 & 9 & 6 \\
\hline
\end{tabular}




\section{Study behaviors}

Next, study behaviors were examined as a function of age and study time. For these analyses, study behavior was coded into four categories: no note-taking or underlining, underlining only, note-taking only, both note-taking and underlining. Cell frequencies are displayed in Table 1. As can be seen, note-taking was the most popular strategy for fifth and seventh graders in both study time conditions. Adult subjects underlined and took notes with approximately equal frequency.

An analysis of recall of most important units (A) as a function of study behavior within the additional study time condition indicated that note-taking was a useful strategy for fifth and seventh graders ( $M=0.62$ for note-takers; 0.42 for those who used no strategy). In contrast, neither note-taking nor underlining benefited adults with additional study time $(M=0.60$ for note-takers, 0.62 for underliners, and 0.71 for adults who used no strategy). Most of the subjects who employed both note-taking and underlining were either fifth graders or older adults. The dual strategy was evidently not effective in aiding recall: $M=0.46$ for those who both underlined and took notes.

Recall of A units in the immediate recall condition did not significantly vary as a function of study behavior $(M=0.61$ for note-takers, 0.60 for underliners, and 0.60 for those who did neither). We suggest that insufficient time was provided in the immediate recall condition for subjects to efficiently use a strategy to help improve recall; thus subjects who simply focused on the text remembered just as well as those who busied themselves using overt study strategies.

\section{Discussion}

Our results, while not replicating those of Brown and Smiley (1978), nevertheless provided partial confirmation of their findings. Subjects in all age groups recalled a greater number of important than unimportant text units. Furthermore, adults showed clear distinctions among all four importance levels in their recall protocols, while fifth and seventh graders did not. However, additional study time resulted in improved recall of important units only for the young adults.

Moore and O'Driscoll (1983), who failed to find improved recall of any units with additional study time, hypothesized that their Papua New Guinean subjects may have lacked metacognitive knowledge about effective strategies in comparison to Brown and Smiley's American subjects: While $76 \%$ of Brown and Smiley's eleventh and twelfth grade subjects took notes or underlined, only $9 \%$ of the Papua New Guinean students engaged in observable study behavior. In the present study, $76 \%$ of subjects in the delayed condition and $63 \%$ of those in the immediate recall condition either took notes or underlined. Note-taking was more popular than underlining, particularly among children. However, study behavior resulted in improved recall only in the additional study time condition, and only for fifth and seventh graders.

\section{Study behaviors and cognitive processing}

Research in study behaviors indicates that underlining and note-taking lead to better recall of texts, but are no more effective than other study strategies (see Anderson \& Armbruster, 1984, for a review). Because underlining and note-taking require additional processing of text material, it is likely that this additional processing is responsible for improved recall, rather than the study behaviors themselves. In a recent investigation of cueing and subsequent text recall, readers recalled the most when they actively selected material to underline (van Hout Wolters, 1987). Van Hout Wolters had secondary students read and recall texts in three conditions: with previously teacher-selected material underlined, with instruc- 
tions to underline as they read, or with no underlinings and no instructions to underline. Students remembered the most when they underlined themselves. It should be especially noted that students in the teacher-cued condition, who had the benefit of important information highlighted for them, performed approximately the same as controls. Furthermore, reading times of both underlined and non-underlined phrases were greatest in the learner-cueing condition (von Hout Wolters, 1987). Underlining evidently resulted in a more active processing of the text, indicated by slower reading time, and resulting in superior recall.

Although study behaviors were only associated with improved recall for our fifth and seventh graders, we consider our results to be consistent with those of von Hout Wolters, because of differences in task demands. Her teenage subjects read four-paged texts about tropical agricultural products, appropriate to their reading level. In contrast, we imagine that our adult subjects found our fourth-grade fairy tales to be easy reading. We suggest that in the present study, text processing was more closely related to the use of overt strategies for children than for adults. That is, adult subjects who simply read in detail and concentrated on the text remembered as much as adults who took notes or underlined. In contrast, children who neither took notes nor underlined recalled less than their peers. Thus, their level of processing was quite likely directly associated with their use of overt strategies.

Seventh graders recalled more total units than all other age groups, independent of study time conditions. Seventh graders and young adults recalled a greater number of important units than fifth graders and older adults. We suggest that two factors might be responsible for the excellent performance of seventh graders, particularly in comparison to older adults. First, our seventh graders were Gymnasien students, thus representing the top $30 \%$ academically of their age group; adult sampling was random. Second, the median age of the young adult group was estimated to be 21 . Therefore, only the older adult group was substantially removed from the schooling experience. Although all adult subjects were participating in continuing education classes, the older adults presumeably had much less recent exposure to academic situations and tasks than the other three age groups. Restricted study time may also have influenced the inferior performance of older adults. That is, fifth graders and seventh graders were allowed 8 additional minutes study time in the delayed condition, while adults were only allowed 5 additional minutes. This time constraint may have placed the oldest adults at a disadvantage.

\section{Text processing and metacognition}

A final point concerns the question of whether study strategies like underlining and note-taking are indicative of metacognitive knowledge about text processing, as Brown and Smiley (1978) suggested. Unlike Brown and Smiley, we were unable to find clear evidence that subjects differentiated among importance levels in their underlining and note-taking behaviors. Thus, more fine-grained analyses concerning the interrelationships among study strategies, importance levels chosen, and resulting recall could not be conducted. However, we are far from convinced that the evidence presented by Brown and Smiley can be inequivocably interpreted in terms of metacognitive effects. An underlying assumption of the hypothesized link among study behaviors, recall patterns, and metacognitive knowledge is that sophisticated readers primarily remember as a function of the importance of text units. However, the «importance» of text material varies from reader to reader and across task demands. Furthermore, other factors influence recall. Denhière and Legros examined recall of narrative texts by high school students as a function of relative importance and nature of the statements. They reported the following frequencies of recall: narrative $>$ action description $>$ cohesive state description $>$ ornamental state description. Thus, memorisation of information varied both as a function of its importance and its semantic role in the story (Denhière \& Legros, 1987).

The assumption that older readers' recall patterns reflects that their superior metacognitive knowledge only seems convincing if study behavior closely corresponds with the 
subjects' verbal reports concerning their knowledge about text processing. Thus, the distinction between cognitive and metacognitive strategies in this situation only holds if it can be clearly illustrated that specific study behaviors are deliberate, metacognitively-informed actions.

\section{References}

Anderson, T. H., \& Armbruster, B. B. (1984). Studying. In D. Pearson (Ed.), Handbook of reading research (pp. 657-679). New York: Longman.

Brown, A. L., \& Smiley, S. S. (1977). Rating the importance of structural units of prose passages: A problem of metacognitive development. Child Development, 48, 1-8.

Brown, A. L., \& Smiley, S. S. (1978). The development of strategies for studying texts. Child Development, 49, 1076-1088.

Brown, A. L., Smiley, S. S., Day, J. D., Townsend, M., \& Lawton, S. C. (1977). Intrusion of a thematic idea in children's comprehension and retention of stories. Child Development, 48, 1454-1466.

Brown, A. L., Smiley, S. S., \& Lawton, S. C. (1978). The effects of experience on the selection of suitable retrieval cues for studying texts. Child Development, 49, 829-835.

Denhière, G. (1980). Narrative recall and recognition by children. In F. Klix \& J. Hoffmann (Eds.), Cognition and Memory (pp. 226-236). Berlin: Deutscher Verlag.

Denhière, G., \& Legros, D. (1987). L'interaction narration * description dans le récit I. Etude de la mémorisation de différents types de séquences descriptives. L'Année Psychologique, 87, 345-362.

Denhière, G., \& Le Ny, J. F. (1980). Relative importance of meaningful units in comprehension and recall of narratives by children and adults. Poetics, 9, 147-161.

Johnson, R. E. (1970). Recall of prose as a function of the structural importance of linguistic units. Journal of Verbal Learning and Verbal Behavior, 9, 12-20.

Moore, D. W., \& O'Driscoll, M. P. (1983). Strategies for studying texts: A comparison of Papua New Guinean and American research findings. Journal of Educational Psychology, 75, 460-464.

van Hout Wolters, B. (1987, September). Selecting and cueing key phrases in instructional texts. Second European Conference on Learning and Instruction, Tübingen, West Germany.

\section{Les effets de l'âge, du temps d'étude et de \\ l'importance relative de l'information sur les strategies d'apprentissage et la mémorisation de textes}

Une recherche ayant pour but d'étudier les activités d'étude et le rappel d'un texte narratif en fonction de l'âge, du temps d'étude et de l'importance relative des unités textuelles, a été réalisée. Quatre groupes de sujets: deux groupes d'enfants âgés en moyenne de $11 ; 5$ ans et 13; 8 ans, et deux groupes d'adultes âgés de 19 à 35 ans et de 36 à 70 ans ont participé à cette expérience. Une moitié des sujets de chaque groupe effectuait un rappel immédiat alors que l'autre moitié recevait un temps supplémentaire pour préparer, comme ils le souhaitaient: prise de notes, soulignement, etc., ..., leur rappel. Les résultats montrent que les quatre groupes de sujets rappellent davantage d'informations importantes que non importantes, cet effet de l'importance relative de l'information étant indépendant de l'âge et des conditions expérimentales. Les activités de préparation du rappel varient systématiquement en fonction de l'âge des sujets: alors que les comportements de soulignement et de prise de notes sont également fréquents chez les adultes, les enfants utilisent davantage la prise de notes. Avec un temps supplémentaire d'étude, les enfants et les adultes âgés modifient leur comportement de préparation du rappel, ce que ne font pas les jeunes adultes.

Key words: Text recall, Study strategies, Relative importance, Life span development. 
Beth E. Kurtz. Max Planck Institute for Psychological Research, Leopoldstrasse 24, D-8000 Munich 40, F.R.G.

Current theme of research:

Development of metacognitive processes in children, and their environmental correlates.

Most relevant publications in the field of Educational Psychology:

Borkowski, J. G., \& Kurtz, B. E. (1987). Executive control and metacognition. In J. G. Borkowski \& J. D. Day (Eds.), Cognition and intelligence in special children: Comparative approaches to retardation, learning disabilities, and giftedness (pp. 123-152). Norwood, N. J.; Ablex Publishing Corp.

Kurtz, B. E., \& Borkowski, J. G. (1987). Development of strategic skills in impulsive and reflective children: A longitudinal study of metacognition. Journal of Experimental Child Psychology, 43, 129-148.

Kurtz, B. E., \& Borkowski, J. G. (1984). Children's metacognition: Exploring relations among knowledge, process, and motivational variables. Journal of Experimental Child Psychology, 37, 335-354.

Schneider, W., Borkowski, J. G., Kurtz, B. E., \& Kerwin, K. (1986). Metamemory and motivation: A causal analysis of strategy use in German and American children. Journal of Cross-Cultural Psychology, 17, 315-336.

Wolfgang Schneider. Max Planck Institute for Psychological Research, Leopoldstrasse 24, D-8000 Munich 40, F.R.G.

Current theme of research:

Memory development. Development of metacognitive processes. Early prediction of school achievement.

Most relevant publications in the field of Educational Psychology:

Schneider, W. (1985). Developmental trends in the metamemory-memory behavior relationship: An integrative review. In: D. Forrest-Pressley, G. McKinnon \& T. G. Waller (Eds.), Cognition metacognition, and performance (pp. 57-109). New York: Academic Press.

Schneider, W. (1986). The role of conceptual knowledge and metamemory in the development of organizational processes in memory. Journal of Experimental Child Psychology, 42, 218-236.

Schneider, W., \& Pressley, M. (in press). The development of memory and metamemory in children. New York: Springer-Verlag.

Schneider, W., \& Treiber, B. (1984). Classroom differences in the determination of achievement changes. American Educational Research Journal, 21, 195-211. 